\title{
Efficacy of Tobacco Leaves (Nicotiana tabacum) as Anaesthetic Agent on the Juveniles and Adults of African Catfish Clarias gariepinus (Burchell 1822)
}

\author{
Moshood K. Mustapha* and Jamaldeen A. Aileru
}

Department of Zoology, Faculty of Life Sciences, University of Ilorin, PMB 1515, Ilorin, Nigeria

Received $9^{\text {th }}$ June, 2021, Accepted $11^{\text {th }}$ September, 2021

DOI: 10.2478/ast-2021-0007

${ }^{*}$ Corresponding author

Moshood K. MUSTAPHA E-mail: kmoshood@unilorin.edu.ng

Tel: +2348035797590

\begin{abstract}
Various fisheries and aquacultural practices such as handling, transportation, tagging and so on stress fish. To minimise the stress, fish should be anaesthetise using agents that is safe, cheap in cost and extraction, effective and readily available and which should induce anaesthesia and recovery within few minutes as compared to synthetic anaesthetics. This study investigated the efficacy of tobacco leaves extract (Nicotiana tabacum) as an anaesthetic agent on Clarias gariepinus juveniles and adults. Ethanolic extracts of the leaves at $50 \mathrm{mg} \mathrm{L}^{-1}, 100 \mathrm{mg} \mathrm{L}^{-1}, 150 \mathrm{mg} \mathrm{L}^{-1}$ and $200 \mathrm{mg} \mathrm{L}^{-1}$ were used to anaesthetise juveniles and adults of the fish in order to vary the effects of increasing concentrations on the fish. Least induction time in juveniles was $166.72 \pm 7.15 \mathrm{~s}$ recorded in $200 \mathrm{mg} \mathrm{L}^{-1}$, while highest induction time of $476.32 \pm 3.29 \mathrm{~s}$ was in $50 \mathrm{mg} \mathrm{L}^{-1}$. In adult, least induction time was $440.99 \pm 2.42 \mathrm{~s}$ in $200 \mathrm{mg} \mathrm{L}^{-1}$ concentration, and highest was $916.75 \pm 6.65 \mathrm{~s}$ in $50.00 \mathrm{mg} \mathrm{L}^{-1}$. Highest and lowest recovery times in juveniles were $1078.68 \pm 19.80 \mathrm{~s}$ and $751.21 \pm 7.65 \mathrm{~s}$ in $200 \mathrm{mg} \mathrm{L}^{-1}$ and $50.00 \mathrm{mg} \mathrm{L}^{-1}$ respectively. In adult, least recovery time was $361.83 \pm 5.14 \mathrm{~s}$ in $50.00 \mathrm{mg} \mathrm{L}^{-1}$, while $200.00 \mathrm{mg} \mathrm{L}^{-1}$ produced the highest recovery time at $548.45 \pm 7.78 \mathrm{~s}$. $200 \mathrm{mg} \mathrm{L}^{-}$ ${ }^{1}$ concentration of tobacco extract was the effective concentration, as it induces anaesthesia within 3 minutes and recovery within 9 minutes with no mortality. These high induction and recovery times may be due to scalessness and well vascularised skin of the fish and its high body lipid content which make nicotine to diffuse faster in and out of the body. $200.00 \mathrm{mg} \mathrm{L}^{-1}$ ethanolic extracts of tobacco leaves could be used to anaesthetise fish as it is safe, low cost in terms of purchase and extraction, readily available, biodegradable (without residual effect), eco-friendly and efficient. It can serve as an alternative to expensive, toxic, scarce MS-222 or clove oil in fisheries and aquaculture.
\end{abstract}

Keywords: Clarias gariepinus; nicotine; tobacco; anaesthetics; induction and recovery. 


\subsection{Introduction}

Fish feel pain and suffering (Volpato et al. 2009). Several factors that bring pain and impair welfare of fish have been identified by Mustapha (2013; 2014). Among them are various aquacultural practices which include holding, handling, transportation, weighing, sorting, grading and harvesting of fries, fingerlings, juveniles and adults, as well as induced breeding, hybridization, selective breeding, treatment of parasites and diseases and during slaughter. So also, in fish research, such as measurements of length and weight, and other parameters that involve capture and release of the fish back into the water, marking or tagging, etc. All of these bring stress and sometimes physical injury to the fish. The effects of this stress on fish often lead to decrease in productivity, morphological and behavioural abnormalities, physiological and homeostatic imbalance and eventually mortality (Mustapha, 2014).

In order to minimise stress in fish whether in aquaculture or research, it is humane and welfare imperative to anaesthetise them using anaesthetic agent(s) that is effective at low dosage, water soluble, safe, cheap, readily available, easy to use, with little or no side effects on the fish, fish habitat and the administrator of the anaesthetic agent. Anaesthetics are chemical or physical agents which are used first to calm (sedate) and then cause successive loss of mobility, equilibrium, consciousness and reflex action (Summerfelt and Smith, 1990). Anaesthesia in fish should induce rapidly, preferably in less than 3 minutes, with minimum accompanying hyperactivity or other stress. It should maintain the fish in the chosen state, and provide proper immobilisation and effective analgesia. Recovery should be rapid, substantially complete after about 5 minutes in clean water, without prolonged ataxia or other undesirable features (Ross and Ross, 2008).

Historically, fish anaesthesia was based on the use of chemical agents such as ether, chloroform, methanol, urethane and cocaine. Many of these are no more in use because of their toxicity or carcinogenicity, inefficacy and adverse effects on fish physiology and water quality (Ross and Ross, 2008). Later, chemicals such as benzocaine, tricaine methanesulfonate (MS 222), 2-methylquinoline (Quinaldine), 2phenoxyethanol, etomidate, metomidate, propanidid, barbiturates, propoxate, 4-styrylpyridine, amylobarbitone, auinalbarbitone, aentothal, ahoral hydrate, chlorbutanol, sodium cyanide, lidocaine methyl pentynol, piscaine, propoxate, tribromoethanol (TBE), tertiary butyl alcohol (TBA), tertiary amyl alcohol (TAA) have been tried as fish anaesthetic agents (Ross and Ross, 2008). MS 222 has remained the most popular of the fish anaesthetics probably due to its approval by the American Food and Drug Administration (FDA).

In spite of its wide use, MS 222 has its own health and environmental hazards; it is also expensive and not easily available in developing countries. This has led to research in 'green anaesthetics' where crude extracts of plants materials are used as fish anaesthetics (Mgbenka and Ejiofor, 1998). Many plants extracts has been tested for their anaesthetic properties in fish. The most popular of such plant is Syzygium aromaticum (i.e. Eugenia aromaticum) or Eugenia caryophyllata which produces clove oil. Ross and Ross (2008), Javahery et al. (2012) have comprehensively reviewed clove oil as fish anaesthetic agent and they reported its major advantage has been relatively inexpensive, not unpleasant to handle and has few harmful effects for humans under normal conditions. However, Velisek (2005) noted its disadvantage as its relatively low therapeutic index, i.e. the ratio between the therapeutic and the toxic concentrations. The plant Syzygium aromaticum (i.e. Eugenia aromaticum) or Eugenia caryophyllata which produces the clove oil is not native or grown in many countries of the world, thus, the oil may not be available in these countries, and even if available, will be expensive.

This study investigates the potentials and efficacy of locally available (in Nigeria) tobacco leaves (Nicotiana tabacum) extract as anaesthetic agent on the juveniles and adult of African catfish Clarias gariepinus (Burchell, 1822) and as an alternative to scarce and expensive Tricaine methanesulfonate (MS-222) or even natural products such as clove oil.

\subsection{Experimental}

\section{Experimental fish}

One hundred and fifty Clarias gariepinus (a high valued aquacultural fish species) comprising seventy five juveniles and seventy five adults of both sexes with mean weight of $5.63 \pm 0.42 \mathrm{~g} ; 1.10 \pm 0.21 \mathrm{~kg}$ respectively were acquired from the Kwara State Ministry of Agriculture and Natural Resources, Ilorin, Nigeria for the study. They were conveyed in 50L oxygenated tanks to the Fisheries and Aquaculture Laboratory of the Department of Zoology, University of Ilorin, Ilorin, Nigeria, where they were acclimatized for two weeks. During the period of acclimatization, the fish were fed with highly nutritious coppens feed containing $42 \%$ crude protein. The fish were fed two times daily at the rate of $5 \%$ body weight.

\section{Experimental plants}

Tobacco (Nicotiana tabacum) leaves were collected from the farmlands in Ilorin, Nigeria. The tobacco leaves were air dried under ambient temperature, pulverized into fine particles $(<250 \mu \mathrm{m})$ with a blender and stored in an air-tight container.

\section{Extraction}

Prior to extraction, pulverized leaves of Nicotiana tabacum were weighed using a mettler balance, and $200 \mathrm{~g}$ of the sample was taken for extraction. Two litres of $50 \%$ ethanol (solvent) was mixed with the sample in a conical flask covered with aluminium foil and placed in a reciprocating shaker for 24 hours at $200 \mathrm{rpm}$ for through mixing and for the extract to completely dissolve in the solvent. The extract was sieved using a white bolting cloth, and then filtered using a vacuum pressure pump. The solvent from the extract was separated using a rotary evaporator in a boiling water bath. The extraction was stopped when a slurry residue of the filtrate was seen and this was collected into an air-tight container (Kantaporn, 2021).

\section{Anaesthetic bath and recovery}

The experiment has four treatments and was done in triplicates for each of the juvenile and adult groups. Both treatment and recovery water were taken from the tank, where the fish were maintained and both bath systems were aerated throughout the procedure. During the experiment, a number of guidelines recommended by Hicks (1989) were followed such as 24-hour diet beforehand, properly aerated anaesthetic bath, same temperature in bath as in breeding tanks, and thoroughly aerated recovery bath flowing through open circuit.

Thirty $2 \mathrm{~L}$ anaesthetic tanks ( 15 for juveniles and 15 for adults) were set up containing water and ethanolic extract of tobacco leaves at 50 
$\mathrm{mg} \mathrm{L}^{-1}, 100 \mathrm{mg} \mathrm{L}^{-1}, 150 \mathrm{mg} \mathrm{L}^{-1}, 200 \mathrm{mg} \mathrm{L}^{-1}$ and $0.00 \mathrm{mg} \mathrm{L}^{-1}$ (no anaesthetic agent). The dosage concentrations selected for the experiment followed Weber et al. (2009). Each concentration was added to each of the four experiment tanks before the introduction of fish. 5 juvenile and 5 adult fish were introduced immediately into each tank so as for drug to be absorbed through the gills and gets into the blood stream as quick as possible as well as into the $0.00 \mathrm{mg} \mathrm{L}^{-1}$ (no anaesthetic agent) tank.

When the fishes reached the tank containing the anaesthetic agent, induction time (when the fishes sank motionless to the bottom with total loss of balance and loss of opercula movement) was measured using a stopwatch in seconds. After this stage of anaesthesia, the fishes were removed from anaesthetic tank and transferred to the recovery tank containing clean well aerated water. The recovery time is the period from the time when an anesthetised fish is placed in a recovery tank until it recovers from anesthetization with full equilibrium motion, opercula movement and normal swimming. Recovery time was also recorded in seconds and the fishes were maintained in there for $48 \mathrm{~h}$ in order to observe possible mortalities, morphological and behavioural abnormalities that could arise from the effect of the tobacco leaves anaesthetics.

\section{Water quality parameters}

Temperature, $\mathrm{pH}$, Total Dissolved Solids and Conductivity of the water were measured using Hanna HI 98129 pH/EC/TDS/Temperature combined tester, while dissolved oxygen and ammonia were measured using Hanna Multiparameter Bench Photometer for Laboratories Model HI 83200-02.

\section{Statistical analysis}

Data was analysed using one way ANOVA. Significance difference $(\mathrm{P}<0.05)$ among the means of the treatments was determined by Turkey's multiple comparison tests using SPSS (Windows, Version 20.0).

\subsection{Results}

\section{Induction time}

The induction time of $C$. gariepinus juveniles exposed to various concentration of ethanolic extract of tobacco leaves ( $N$. tabacum) is presented in Table 1.

The fishes were normal in their behavioural activities such as swimming, balance, opercula movement and general movement of the tail and fins at $0.00 \mathrm{mg} \mathrm{L}^{-1}$ concentration which served as the control. Least induction time of $166.72 \pm 7.15 \mathrm{~s}$ was recorded in $200 \mathrm{mg} \mathrm{L}^{-1}$ concentration of the ethanolic extract of $N$. tabacum where there was total loss of movement/swimming, and the fish sank motionless at the bottom of the tank. The highest induction time of $476.32 \pm 1.423 .29 \mathrm{~s}$ for the anaesthetic agent was in $50 \mathrm{mg} \mathrm{L}^{-1}$ concentration, where there was total loss of movement in the fish, while the induction time in control was $0.00 \pm 0.00$ s. There was significant difference $(\mathrm{P}<0.05)$ in the induction times in all the four concentrations (Table 1). No mortality of the fish species was recorded during the induction time in all the four treatments.

The induction time of the adult $C$. gariepinus exposed to various concentrations of ethanolic extract of tobacco leaves ( $N$. tabacum) is presented in Table 2. Just like the juveniles, fishes showed normal activities in $0.00 \mathrm{mg} \mathrm{L}^{-1}$, the quick effect (induction time) of the anaesthesia was felt by the fish at $200 \mathrm{mg} \mathrm{L}^{-1}$ concentration, where total loss of movement was observed at $440.99 \pm 2.42 \mathrm{~s}$. $50.00 \mathrm{mg} \mathrm{L}^{-1}$ concentration produced the most induction time for the anaesthetic to be effective with total loss of movement at $916.75 \pm 6.65 \mathrm{~s}$. There was significant difference $(\mathrm{P}<0.05)$ in the induction times among all the four concentrations (Table 2). No mortality was observed in the fish during the induction time in all the four treatments.

\section{Recovery time}

Table 3 shows the recovery time of the juveniles of $C$. garepinus exposed to various concentration of ethanolic extract of tobacco leaves (N. tabacum). The highest time of recovery was in $200 \mathrm{mg} \mathrm{L}^{-1}$ concentration, where normal swimming movement began at 1078.68 \pm 19.80 s. The lowest recovery time was in $50.00 \mathrm{mg} \mathrm{L}^{-1}$ concentration where normal swimming began at $751.21 \pm 7.65$ s. There was significant difference $(\mathrm{P}<0.05)$ in the recovery times among all the four concentrations. No mortality was observed in the fish during the recovery time in all the four treatments.

Table 4 shows the recovery time of the adult $C$. garepinus exposed to various concentration of ethanolic extract of tobacco leaves $(N$. tabacum). The least recovery time was in $50.00 \mathrm{mg} \mathrm{L}^{-1}$ concentration, where normal swimming movement began at $361.83 \pm 5.14 \mathrm{~s}$. 200.00 $\mathrm{mg} \mathrm{L}^{-1}$ concentration showed the highest recovery time at 548.45 \pm 7.78 s. There was significant difference $(\mathrm{P}<0.05)$ in the recovery times among all the four concentrations. No mortality was observed in the fish during the recovery time in all treatments.

\section{Stages and pattern of behavioural responses during anaesthesia}

The observed stages and pattern of behavioural responses of the juveniles and adults of $C$. gariepinus to ethanolic extract of tobacco leaves ( $N$. tabacum) during induction and recovery periods is presented in Table 5. Induction starts with slow swimming of the fish (stage I) and ends up with total loss of swimming (stage IV), while recovery starts with movement of opercula (stage I) and ends with normal swimming of the fish (stage IV).

\section{Water quality parameters}

The water quality in the control and treatment tanks of $C$. gariepinus exposed to four different concentrations of ethanolic extract of tobacco leaves ( $N$. tabacum) is presented in Table 6. Temperature ranged between 28.50 and $28.60{ }^{\circ} \mathrm{C}$, $\mathrm{pH}$ was between 7.20 and 7.50, dissolved oxygen concentration ranged from 7.60-7.90 mg/l, ammonia concentration was between 0.30 to $0.32 \mathrm{mg} / \mathrm{l}$, conductivity ranged from 133-178 $\mu \mathrm{S} / \mathrm{cm}$ and Total Dissolved Solids was between 89-119 $\mathrm{mg} / \mathrm{l}$. There was no significant $(\mathrm{P}<0.05)$ change in the water quality between the control and exposure concentrations.

Ethic approval and consent to participate

All applicable international, national, and institutional guidelines for the care and use of animals were followed. All procedures performed in this study involving the fish Clarias gariepinus (Burchell, 1822) were in accordance with the ethical standards of the University of Ilorin, Ilorin, Nigeria, where the study was conducted and who granted the ethical approval for the conduct of the research. 
Table 1: Induction time of C. gariepinus juveniles exposed to various concentration of ethanolic extract of tobacco leaves (Nicotiana tabacum)

\begin{tabular}{cccccc}
\hline $\begin{array}{c}\text { Concentration } \\
\text { mg/l }\end{array}$ & Slow swimming & Loss of equilibrium & $\begin{array}{c}\text { Loss of opercula } \\
\text { movement }\end{array}$ & $\begin{array}{c}\text { Total loss of } \\
\text { movement }\end{array}$ & $\begin{array}{c}\text { Mortality } \\
0.00 \pm 0.00\end{array}$ \\
\hline 0.00 & $0.00 \pm 0.00$ & $0.00 \pm 0.00$ & $0.00 \pm 0.00$ & $0.00 .00^{\mathrm{a}}$ \\
50.00 & $221.96 \pm 5.18^{\mathrm{d}}$ & $240.70 \pm 3.69^{\mathrm{d}}$ & $326.69 \pm 5.43^{\mathrm{d}}$ & $476.32 \pm 3.29^{\mathrm{d}}$ & $0 \pm 0.00^{\mathrm{a}}$ \\
100.00 & $155.47 \pm 4.58^{\mathrm{c}}$ & $208.03 \pm 2.71^{\mathrm{c}}$ & $280.86 \pm 4.93^{\mathrm{c}}$ & $309.12 \pm 1.80^{\mathrm{c}}$ & $0 \pm 0.00^{\mathrm{a}}$ \\
150.00 & $85.01 \pm 1.99^{\mathrm{b}}$ & $176.14 \pm 4.83^{\mathrm{b}}$ & $191.99 \pm 4.24^{\mathrm{b}}$ & $208.12 \pm 3.63^{\mathrm{b}}$ & $0 \pm 0.00^{\mathrm{a}}$ \\
200.00 & $51.33 \pm 1.42^{\mathrm{a}}$ & $99.36 \pm 3.87^{\mathrm{a}}$ & $131.36 \pm 5.15^{\mathrm{a}}$ & $166.72 \pm 7.15^{\mathrm{a}}$ & $0 \pm 0.00^{\mathrm{a}}$ \\
\hline
\end{tabular}

Mean within the row with different superscripts are significant $(\mathrm{P}<0.05)$

$$
\mathrm{N}=75
$$

Mean \pm SD

Table 2: Induction time of C. gariepinus adults exposed to various concentration of ethanolic extract of tobacco leaves (Nicotiana tabacum)

\begin{tabular}{|c|c|c|c|c|c|}
\hline $\begin{array}{c}\text { Concentration } \\
\mathrm{mg} / \mathrm{l}\end{array}$ & Slow swimming & Loss of equilibrium & $\begin{array}{c}\text { Loss of opercula } \\
\text { movement }\end{array}$ & $\begin{array}{c}\text { Total loss of } \\
\text { movement }\end{array}$ & Mortality \\
\hline 0.00 & $0.00 \pm 0.00$ & $0.00 \pm 0.00$ & $0.00 \pm 0.00$ & $0.00 \pm 0.00$ & $0 \pm 0.00^{a}$ \\
\hline 50.00 & $521.35 \pm 11.71^{\mathrm{d}}$ & $626.46 \pm 5.71^{d}$ & $821.01 \pm 4.26^{\mathrm{d}}$ & $916.75 \pm 6.65^{d}$ & $0 \pm 0.00^{\mathrm{a}}$ \\
\hline 100.00 & $382.27 \pm 4.42^{\mathrm{c}}$ & $569.88 \pm 4.98^{c}$ & $656.75 \pm 4.96^{c}$ & $807.37 \pm 5.79^{c}$ & $0 \pm 0.00^{\mathrm{a}}$ \\
\hline 150.00 & $278.77 \pm 4.95^{b}$ & $384.94 \pm 4.07^{b}$ & $528.28 \pm 7.21^{b}$ & $606.39 \pm 6.20^{\mathrm{b}}$ & $0 \pm 0.00^{\mathrm{a}}$ \\
\hline 200.00 & $219.28 \pm 4.50^{\mathrm{a}}$ & $327.65 \pm 4.09^{a}$ & $401.39 \pm 3.01^{a}$ & $440.99 \pm 2.42^{a}$ & $0 \pm 0.00^{\mathrm{a}}$ \\
\hline
\end{tabular}

Mean within the row with different superscripts are significant $(\mathrm{P}<0.05)$

$$
\mathrm{N}=75
$$

Mean \pm SD

\begin{tabular}{|c|c|c|c|c|c|}
\hline $\begin{array}{c}\text { Concentration } \\
\mathrm{mg} / \mathrm{l}\end{array}$ & $\begin{array}{c}\text { Beginning of } \\
\text { opercula movement }\end{array}$ & Irregular balance & Equilibrium recovery & Normal swimming & Mortality \\
\hline 0.00 & $0.00 \pm 0.00$ & $0.00 \pm 0.00$ & $0.00 \pm 0.00$ & $0.00 \pm 0.00$ & $0 \pm 0.00^{\mathrm{a}}$ \\
\hline 50.00 & $476.21 \pm 5.21^{a}$ & $572.61 \pm 6.17^{a}$ & $597.27 \pm 4.01^{\mathrm{a}}$ & $751.21 \pm 7.65^{a}$ & $0 \pm 0.00^{\mathrm{a}}$ \\
\hline 100.00 & $587.27 \pm 4.92^{\mathrm{b}}$ & $693.44 \pm 8.34^{\mathrm{b}}$ & $784.85 \pm 7.96^{\mathrm{b}}$ & $944.10 \pm 10.31^{\mathrm{b}}$ & $0 \pm 0.00^{\mathrm{a}}$ \\
\hline 150.00 & $612.30 \pm 3.00^{c}$ & $773.32 \pm 12.72^{\mathrm{c}}$ & $812.86 \pm 11.04^{c}$ & $1023.50 \pm 13.25^{c}$ & $0 \pm 0.00^{\mathrm{a}}$ \\
\hline 200.00 & $712.85 \pm 5.06^{\mathrm{d}}$ & $803.29 \pm 3.56^{\mathrm{d}}$ & $903.44 \pm 10.36^{d}$ & $1078.68 \pm 19.80^{\mathrm{d}}$ & $0 \pm 0.00^{\mathrm{a}}$ \\
\hline
\end{tabular}

Table 3: Recovery time of C. gariepinus juveniles exposed to various concentration of ethanolic extract of tobacco leaves (Nicotiana tabacum

Mean within the row with different superscripts are significant $(\mathrm{P}<0.05)$

$\mathrm{N}=75$

Mean \pm SD

\begin{tabular}{|c|c|c|c|c|c|}
\hline $\begin{array}{c}\text { Concentration } \\
\mathrm{mg} / \mathrm{l}\end{array}$ & $\begin{array}{c}\text { Beginning of } \\
\text { opercula movement }\end{array}$ & Irregular balance & Equilibrium recovery & Normal swimming & Mortality \\
\hline 0.00 & $0.00 \pm 0.00$ & $0.00 \pm 0.00$ & $0.00 \pm 0.00$ & $0.00 \pm 0.00$ & $0 \pm 0.00^{a}$ \\
\hline 50.00 & $221.97 \pm 4.00^{\mathrm{a}}$ & $262.81 \pm 3.35^{\mathrm{a}}$ & $309.58 \pm 4.27^{a}$ & $361.83 \pm 5.14^{\mathrm{a}}$ & $0 \pm 0.00^{a}$ \\
\hline 100.00 & $249.39 \pm 7.32^{\mathrm{b}}$ & $294.28 \pm 4.61^{b}$ & $359.25 \pm 8.35^{b}$ & $426.42 \pm 6.48^{b}$ & $0 \pm 0.00^{a}$ \\
\hline 150.00 & $292.98 \pm 4.13^{c}$ & $338.31 \pm 6.79^{c}$ & $381.36 \pm 4.56^{c}$ & $456.18 \pm 5.40^{c}$ & $0 \pm 0.00^{\mathrm{a}}$ \\
\hline 200.00 & $344.23 \pm 5.03^{\mathrm{d}}$ & $410.75 \pm 7.43^{\mathrm{d}}$ & $507.61 \pm 6.19^{d}$ & $548.45 \pm 7.78^{\mathrm{d}}$ & $0 \pm 0.00^{\mathrm{a}}$ \\
\hline
\end{tabular}

Table 4: Recovery time of C. gariepinus adults exposed to various concentration of ethanolic extract of tobacco leaves (Nicotiana tabacum)

Mean within the row with different superscripts are significant $(\mathrm{P}<0.05)$

$\mathrm{N}=75$

Mean \pm SD

Table 5: Observed stages and pattern of behavioural responses of the juveniles and adults of $C$. gariepinus exposed to different concentrations of ethanolic extract of tobacco leaves (N. tabacum) during induction and recovery periods

\begin{tabular}{ccc}
\hline Anaesthesia & Stages & Behavioural responses \\
\hline Induction & I & Slow swimming \\
& II & Loss of equilibrium \\
& III & Total loss of movement \\
& IV & Beginning of opercula movement \\
& & Irregular balance \\
& I & Equilibrium recovery \\
& II & Normal swimming \\
\hline
\end{tabular}


Table 6: Water quality in the control and treatment tanks of $C$. gariepinus exposed to different concentrations of ethanolic extract of tobacco

\begin{tabular}{cccccc}
\multicolumn{5}{c}{ leaves $(N$. tabacum $)$} \\
\hline Parameter & $0.00(\mathrm{mg} / \mathrm{l})$ & $50.00(\mathrm{mg} / \mathrm{l})$ & $100.00(\mathrm{mg} / \mathrm{l})$ & $150.00(\mathrm{mg} / \mathrm{l})$ & $200.00(\mathrm{mg} / \mathrm{l})$ \\
\hline Temperature $(-\mathrm{o})$ & $28.60 \pm 0.01$ & $28.60 \pm 0.01$ & $28.60 \pm 0.01$ & $28.50 \pm 0.01$ & $28.50 \pm 0.01$ \\
pH & $7.50 \pm 0.02$ & $7.20 \pm 0.02$ & $7.26 \pm 0.02$ & $7.39 \pm 0.02$ & $7.41 \pm 0.02$ \\
Dissolved oxygen $(\mathrm{mg} / \mathrm{l})$ & $7.90 \pm 0.01$ & $7.80 \pm 0.01$ & $7.70 \pm 0.01$ & $7.60 \pm 0.01$ & $7.60 \pm 0.01$ \\
Ammonia $(\mathrm{mg} / \mathrm{l})$ & $0.30 \pm 0.01$ & $0.31 \pm 0.01$ & $0.31 \pm 0.01$ & $0.31 \pm 0.01$ & $0.32 \pm 0.01$ \\
Conductivity $(\mu \mathrm{S} / \mathrm{cm})$ & $133 \pm 0.08$ & $142 \pm 0.08$ & $156 \pm 0.08$ & $164 \pm 0.08$ & $178 \pm 0.08$ \\
Total Dissolved Solids $(\mathrm{mg} / \mathrm{l})$ & $89 \pm 0.08$ & $95 \pm 0.08$ & $105 \pm 0.08$ & $110 \pm 0.08$ & $119 \pm 0.08$ \\
\hline
\end{tabular}

\subsection{Discussion}

There is an inverse relationship between concentration of ethanolic extract of tobacco leaves (Nicotiana tabacum) and the induction time on the fish. As the concentration of the ethanolic extract of tobacco leaves increases, induction time decreases. This scenario has been reported by Husen and Sharma (2015), Hoseini and Ghelichpour (2012), and Hseu et al. (1998). This is due to the increasing potent action of the active ingredient of the tobacco leaves (nicotine) on the body system of the fish which impaired the central nervous system causing a knockdown of the musculo-skeletal system of the fish in a very short time (Miller et al. 2013). $200 \mathrm{mg} / \mathrm{l}$ concentration of the anaesthetic is a very effective concentration to the juveniles and adults as it induces anesthesia within 3 minutes and 7 minutes respectively with no mortality recorded in both age groups. These induction times in the fish was achieved because of the scalessness and well vascularised skin of the fish which allowed the active ingredients in the tobacco leaves (nicotine) to diffuse faster into the body aside the oral route. The $200 \mathrm{mg} / \mathrm{l}$ concentration of ethanolic extract of tobacco leaves (Nicotiana tabacum) and the induction and recovery times compared favourably well with Tricaine methanesulfonate (MS-222) as reported by Ross and Geddes (1979) and Mercy et al. (2013). Most other natural products used as anaesthetic agents showed a longer induction and recovery times (Adebayo and Olufayo, 2017). The induction and recovery times in both juveniles and adults are ideal as it is line with recommendations of Marking and Meyer (1985) and Gilderhus and Marking (1987). The induction time in the adult as compared with the juvenile shows that different induction times exist between juveniles and adult fish species and that anaesthetic agent concentration for juveniles might not be the same for adult as the adult is able to withstand stress more than the juvenile. Also, the juvenile of the fish species has thinner skin which permitted nicotine to diffuse relatively more into the body than the adult. This has also been observed by Ross and Geddes (1979) who showed that $60-70 \mathrm{mg} / \mathrm{l}$ of MS-222 is needed to anaesthetise tilapia fry as against $100-200 \mathrm{mg} / \mathrm{l}$ needed for tilapia adult. The result obtained in this study could well be compared with that of Konar, (1970) where a concentration of $5 \mathrm{~g} / \mathrm{l}$ of nicotine elicited a high degree of excitability and eventual stupor within 5 - 10 min of exposure, Agokei and Adebisi (2010) who noted that the effective concentration of aqueous extract of tobacco was 4/4.5 g/l in adult Oreochromis niloticus. Jegede (2014) suggested the use of ethanolic extract of tobacco Nicotiana tabacum at $2.5 \mathrm{~g} / 10 \mathrm{l}$ of water as an anaesthetic agent in C. gariepinus fingerlings and Dinesh et al. (2017) observed that tobacco leaf dust of up to $75 \mathrm{ppm}$ concentration can be used as a sedative for rohu fingerlings transport. Malstrom et al. (1993) recommended a dosage of $2.5 \mathrm{~g} / \mathrm{l}$ for quick anaesthetization of halibut from which fish recovered in $11 \mathrm{~min}$.

The recovery time of $C$. gariepinus was faster at lower concentrations using the ethanolic extract of tobacco leaves and longer as concentration increases. This has been reported by Ross and Ross (2008). The adult fish recovered faster from the effects of the anaesthetics than the juvenile, this could be due to the oxygen debt acquired during anaesthesia, high body lipid content and scalessness of $C$. gariepinus, which allowed the active ingredients of the tobacco leaves (nicotine) to diffuse out of the body at a faster rate apart from the normal excretion through the kidneys. The time for a full recovery in fish species can range from minutes to days and will depend on the species and drugs used (Ross and Ross 2008). Ideally, recovery should be fast enough so as to minimise stress of the process that necessitated anaesthesia in the first instance. Also, long recovery time could be stressful to the fish as the fish will not be able to perform its metabolic, physiological and behavioural functions on time. Ethanolic extract of tobacco leaves used as anaesthetic agent has shown the recovery to be safe, devoid of mortality, uneventful and fast enough for any fisheries or aquacultural practice to be done in earnest.

The anaesthetic effect of ethanolic extract of tobacco leaves on the $C$. gariepinus produced all the stages of induction and recover (Summerfelt and Smith, 1990) which are also exhibited by MS-222, clove oil or other anaesthetic agents.

The water quality parameters in the treatments were similar to the control, showing that ethnaolic extract of tobacco leaves does not significantly change the water quality to the detriment of the fish been anaesthetised. The water quality parameters were optimal during the fish anaesthesia. This could account for the no mortality recorded during the anaesthesia and the overall success of the anaesthesia procedure.

Tobacco is highly cost effective as compared to MS-222 or clove oil. For instance, $100 \mathrm{~g}$ of MS-222 costs 160 US dollars and $10 \mathrm{ml}$ of $100 \%$ clove oil costs of 15 US dollars, while $1 \mathrm{~kg}$ of tobacco costs 2 US dollars.

\section{Conclusion}

In the light of the fact that fishes undergo stress and feel pain and these can impair their welfare, as there is no way handling, measurement, holding, transportation, weighing, sorting, grading, harvesting, induced breeding, hybridization, selective breeding, treatment of parasites and diseases, slaughtering, measurements of length and weight, marking or tagging, will not be done in aquacultural practices and fisheries research. It is important to lessen their stress and pains by the use of anaesthetics. Various chemical and organic anaesthetics have been tested and in use, but their safety, toxicity, availability, cost etc are of great concern to researchers and fish breeders (aquaculturists) in developing countries. Thus, naturally producing anaesthetics such as tobacco leaves that is safe to human and fish, that can be used in large amount by local fish breeders and which can be released into the natural water bodies without harm or residual effect, 
highly biodegradable, low cost, readily available, easily dispersible in water, eco-friendly, effective and efficient should be used as fish anaesthetic for fisheries researches and aquacultural practices as an alternative to expensive, toxic, scarce MS-222 or clove oil.

\section{Acknowledgement}

The authors thank Kwara State Ministry of Agriculture and Natural Resources, Ilorin, Nigeria for providing the fish samples and the Department of Zoology, University of Ilorin, Ilorin, Nigeria for providing the laboratory space and reagents for the study.

\section{Declaration of Conflict of Interests}

The authors declare no conflict of interests

\section{Authors' Contributions}

Conception: [MKM]

Design: [MKM]

Execution: [JAA]

Interpretation: [JAA]

Writing the paper: $[\mathrm{MKM}]$

\section{References}

Adebayo, S. F., and Olufayo, M. 0., 2017, Anaesthetic effects of Datura stramonium Leaf on Heterobranchus bidorsalis Juveniles. International Journal of Fisheries and Aquatic Studies, 5: 590-593.

Agokei, O. E., and Adebisi, A. A., 2010, Tobacco as an anaesthetic for fish handling procedure, Journal of Medical Plant Research, 4: 1396-1399.

Anna Mercy, T. V., Malika, V., and Sajan, S., 2013, Use of tricaine methanesulfonate (MS-222) to induce anaesthesia in Puntius denisonii (Day, 1865) (Teleostei: Cypriniformes: Cyprinidae), a threatened barb of the Western Ghats, India. Journal of Threatened Taxa, 5: 44144419.

Dinesh, R., Prakash, C., Chadha, N. K., Poojary, N., and Abraham, S., 2017, Does Tobacco (Nicotiana tabacum) Leaf Dust Save the Life of Rohu (Labeo rohita) Fingerlings during Transport? Journal of Aquaculture Research and Development, 8: 474. doi: 10.4172/21559546.1000474

Gilderhus, P. A., and Marking, L. L., 1987, Comparative efficacy of 16 anaesthetic chemicals on rainbow trout. North American Journal of Fisheries Management, 7: 288-292.

Hicks, B., 1989, Anaesthetics: sweet dreams for fragile fish. Canadian Aquaculture, 89: 29-31.

Hoseini, S. M., and Ghelichpour, M., 2012. Efficacy of clove solution on blood sampling and hematological study in Beluga, Huso huso (L.). Fish Physiology and Biochemistry, 38: 493-498.

Hseu, J. R., Yeh, S. L., Chu, Y. T., and Ting, Y. Y., 1998, Comparison of efficacy of five anaesthetics in goldlined sea bream, Sparus sarba. Acta Zoological Taiwanica, 9: 35-41.

Husen, M. A., and Sharma, S., 2015. Immersion of rohu fingerlings in clove oil reduced handling and confinement stress and mortality. International Journal of Fisheries and Aquatic Studies, 2: 299-305.
Javahery, S., Nekoubin, H., and Moradlu, A. H., 2012, Effect of anaesthesia with clove oil in fish (review). Fish Physiology and Biochemistry, 38: 1545-1552. DOI 10.1007/s10695-012-9682-5.

Jegede, T., 2014, Anaesthetic potential of tobacco (Nicotiana tobaccum) on Clarias gariepinus (Burchell 1822) Fingerlings. Journal of Agricultural Science, 6: 86-90.

Kantaporn, K., Adchareeya, K., Wisinee, C., Pornchai, R., and Pensak J., 2021, Extraction of Nicotine from Tobacco Leaves and Development of Fast Dissolving Nicotine Extract Film, Membranes, 11: 403.

Konar, S. K., 1970, Nicotine as a fish poison. Progressive fish culture, 32: 103-104.

Malmstrom, T., Salte, R., Gjoen, M. H., and Linseth, A., 1993, A Practical Evaluation of Metomidate and MS - 222 as anaesthetic for Atlantic Halibut. Aquaculture, 113: 331-338.

Marking, L. L., and Meyer, F. P., 1985, Are better anaesthetics needed in fisheries? Fisheries, 10: 2-5.

Miller, N., Greene, K., Dydinski, A., and Gerlai, R. 2013. Effects of nicotine and alcohol on zebrafish (Danio rerio) shoaling. Behavioural Brain Research, 240: 192-196.

Mustapha, M. K., 2013, Do fish have rights in artisanal fisheries? Zoological Poloniae, 58: 29-36. DOI: 10.2478/zoop-2013-0003.

Mustapha, M. K., 2014, Aquaculture and Fish welfare: Are the rights of fish compromised? Zoological Poloniae, 59: 49-68. DOI: 10.2478/zoop-2014-0005.

Ross, L. G., and Ross, B., 2008, Anaesthetic and sedative techniques for aquatic animals. Blackwell Science, London.

Ross, L. G., and Geddes, J. A., 1979, Sedation of warm water fish species in aquaculture research, Aquaculture, 16: 183-186.

Summerfelt, R. C., and Smith, L. S., 1990, In C. B. Scheck and P. B. Moyle (eds), Methods for Biology, Anaesthesia, Surgery and related Techniques, American Fisheries Society Bethesda, MD.

Velisek, J., Svobodova, Z., Piackova, V., Groch, L., and Nepejchalova, L., 2005, Effects of clove oil anaesthesia on common carp (Cyprinus carpio L.) Veterinary Medicine - Czech. 50: 269-275.

Volpato, G. L., Giaquinto, P. C., Fernandes-de-Castilho, M., Baretto, R. E., and Gonçalvesde-Freitas, E., 2009, Animal welfare: From concepts to reality. Oecologia Brasilia, 13: 5-15.

Weber, R. A., Peleteiro, J. B., García-Martín, L. O., and Aldegunde, M., 2009, The efficacy of 2-phenoxyethanol, metomidate, clove oil and MS222 as anaesthetic agents in the Senegalese Sole (Solea senegalensis Kaup, 1858). Aquaculture, 288: 147-150; doi.10.1016/i.aquaculture.2008.11.024. 